\title{
EFEITO LOCAL DO USO DO SCHINUS TEREBINHTHIFOLIUS E ASSOCIAÇÕES (SANATIVOß) NO PÓS-OPERATÓRIO DE EXODONTIAS DE MOLARES INFERIORES
}

Maria Cecília Fonsêca Azoubel

Neiana Carolina Rios Ribeiro
Doutora em Ciências Médicas pela Faculdade de Medicina da UFC-CE. Professora Adjunta da Escola Bahiana de Medicina e Saúde Pública e dos Cursos de Especialização em Periodontia da ABO-BA.

Cursando o nono semestre de odontologia na Escola Bahiana de Medicina e Saúde Pública. Bolsista da Fundação de Amparo à Pesquisa do Estado da Bahia FAPESB.

\begin{abstract}
Resumo
Objetivo: avaliar clinicamente o efeito tópico do fármaco Sanativo ${ }^{\circledR}$ nos alvéolos de molares inferiores no período pós-operatório. Metodologia: Numa amostragem final de cinquenta e três indivíduos, aleatoriamente divididos nos grupos teste $\left(\right.$ Sanativo $\left.^{\circledR}\right)$, CPA $\left(\right.$ Malvatricin $\left.^{\circledR}\right)$, CPB (Clorexidina) e Controle (Solução fisiológica). Os pacientes foram instruídos a fazer bochechos três vezes ao dia durante 07 dias. Foram considerados os parâmetros: tamanho da ferida e aspecto inflamatório visual em três tempos experimentais (pósoperatório imediato, 48 horas e 07 dias após a intervenção). O teste de Tukey com nível de significância de 5\% foi realizado, além da análise descritiva visual. Resultado: Os resultados não evidenciaram incremento de efeito do uso do Sanativo ${ }^{\circledR}$ sobre os parâmetros avaliados, não comprovando, portanto, benefício adicional no uso do referido medicamento. Conclusão: $\mathrm{O}$ uso do $\operatorname{Sanativo~}^{\circledR}$ não apresentou benefício adicional na redução do tamanho da ferida, não tendo sido, portanto comparável à clorexidina, que confirmou a sua eficácia superior.
\end{abstract}

Palavras-chave: Anacardiaceae; Cirurgia bucal; Cicatrização.

\section{EFFECT OF THE USE OF SCHINUS TEREBINHTHIFOLIUS AND ASSOCIATIONS (SANATIVO®) ON THE POST-SURGERY OF MANDIBULAR MOLARS EXTRACTIONS}

\begin{abstract}
Objectives: evaluate the clinical topical effect of the Sanativo ${ }^{\circledR}$ in the alveolus of mandibular molars during the post-operatory period. Methods: Sixty volunteers were randomly divided into test group (Sanativo ${ }^{\circledR}$ ), PCA $\left(\right.$ Malvatricin $\left.^{\circledR}\right)$, PCB (Clorexidina) e Control (Solução fisiológica). The patients were instructed to realize mouthwashes three times a day during 07 days. The parameters were considered: size of wound and visual inflammatory aspect in three experimental times (immediately after the surgical procedure, 48 hours and 07 day after the intervention. Tukey analysis with significance level of 5\% was performed, beyond the visual descriptive analyses. Results: The results did not point increasing effect by the use of Sanativo ${ }^{\circledR}$ over the evaluated parameters, not proving, therefore, additional benefit in the use of the referred medicine. Conclusions: The use of Sanativo ${ }^{\circledR}$ showed no additional benefit in reducing the size of the wound, was not therefore comparable to chlorhexidine, which confirmed its superior efficacy.
\end{abstract}

Keywords: Anacardiaceae; Surgery; Oral; Wound Healing.

\section{INTRODUÇÃO}

A fitoterapia é uma ciência que se baseia no uso de plantas com propriedades medicinais em suas diferentes formas farmacêuticas. De acordo com a Organização Mundial de Saúde - OMS, cerca de $80 \%$ da humanidade até hoje ainda depende da medicina 
tradicional para o tratamento de doenças. Isto corresponde a aproximadamente cinco bilhões de pessoas e, ainda $85 \%$ desta medicina tradicional envolve o uso de extratos vegetais. ${ }^{(1)}$

Segundo Pessoa, ${ }^{(2)}$ os medicamentos de origem vegetal passaram a alcançar lugar de destaque na profilaxia e tratamento de doenças, ao lado da terapêutica convencional. Este fato ocorre principalmente com os indivíduos de baixo poder aquisitivo, já que os custos são geralmente inferiores, quando comparados aos medicamentos alopáticos produzidos pelas indústrias farmacêuticas.

O Sanativo ${ }^{\circledR}$ (Laperli, Recife, Pernambuco, Brasil) consta como um dos mais antigos fitoterápicos existentes no mercado. Sua utilização data de 1888.

Dentre as espécies vegetais constituintes do Sanativo ${ }^{\circledR}$, a S. terebinthifolius (S.t.) é a mais estudada e utilizada. Conhecida popularmente como Aroeira, o decoto da sua casca é utilizada como hemostática, anti-térmica, podendo ser empregada no tratamento de inflamações uterinas e na cicatrização de feridas, queimaduras e úlceras assim como no tratamento de aftas e gengivites sob a forma de colutórios. ${ }^{(3,4)}$

Estudo realizado por Chung et al. $^{(5)}$ comprovou a atribuição das atividades farmacológicas à diversidade de constituintes químicos desse vegetal. Dentre estas, podemos destacar os taninos que, farmacologicamente, possuem propriedades adstringente, anti-séptica e hemostática.

Quimicamente, as resinas, óleos essenciais, compostos fenólicos, triterpenóides, saponinas, esteróides e os taninos são os principais constituintes das cascas da $S$. terebinthifolius. $^{(6)}$ Este último destacou-se devido à elevada concentração e às atividades biológicas relacionadas, como antiinflamatória, antimicrobiana, anticarcinogênica, antimutagênica e antioxidante. ${ }^{(7,8,9)}$

Outro componente do Sanativo ${ }^{\circledR}$, a Piptadenia colubrina (P.c.) também possui alto teor de taninos (em torno de 32\%). Também conhecida como Angico, Angico Branco/Vermelho, Acácia-angico, Cambuí, e Parica, esse vegetal é empregado popularmente como tônico depurativo, hemostático, adstringente, além de ser bastante utilizado em contusões. ${ }^{(10)}$

Um terceiro composto constituinte do Sanativo $^{\circledR}$ é o extrato da Physalis angulata (P.a.), mais conhecida como Camapu, que através de um estudo realizado por Choi, Hwang ${ }^{(11)}$ comprovou atividade antiinflamatória nos modelos de edema induzido por carragenina, edema de orelha por ácido araquidônico ou artrite induzida por formaldeído. Nesta citada pesquisa, a planta foi utilizada por via oral durante 07 dias, na concentração de $200 \mathrm{mg} / \mathrm{kg}$, em 
camundongos; os estudos sugeriram que esteróides extraídos do camapu possuem potente ação imunomoduladora, agindo através de um mecanismo de ação distinto do observado com o glicocorticóide dexametasona.

A seiva da P.a. possui propriedade calmante e depurativa, sendo útil no tratamento de dores de ouvido e reumatismos. Seus frutos comestíveis são desobstruentes e diuréticos e suas folhas combatem inflamações da bexiga e baço. ${ }^{(10,12)}$

Ainda no que se refere aos extratos associados no Sanativo ${ }^{\circledR}$, o Cereus peruvanius (Mandacaru; Urumbeva) apresenta propriedade antiescorbútica, além de ser utilizada para o tratamento de bronquite. ${ }^{(13)}$

Quanto a avaliação da atividade terapêutica do Sanativo ${ }^{\circledR}$ em modelo animal, Wanderley et al. ${ }^{(14)}$ realizaram estudo que envolveu sessenta e quatro ratos ( $\mathrm{n}=8 /$ grupo) Wistar, os quais foram aleatoriamente divididos nos grupos controle ( $\mathrm{NaCl} 0,9 \%)$, controle positivo (Fibrinase ${ }^{\circledR}$, Cristália), Sanativo ${ }^{\circledR}$ spray $(4 \%)$ e sanativo-extrato spray (4\%). Os animais foram tratados diariamente (2x/dia), durante 14 e 24 dias consecutivos, tendo sido submetidos à aplicações tópicas do Sanativo ${ }^{\circledR}$ na forma de spray e Fibrinase ${ }^{\circledR}$ na forma de pomada, em quantidades suficientes para cobrir a ferida induzida no dorso. Como resultado, foi possível observar que os Sanativo ${ }^{\circledR}$ e o Sanativo-extrato a $4 \%$ produziram diminuição estatisticamente significante da área da ferida aberta $\left(1 \mathrm{~cm}^{2}=100 \%\right)$ nos $4^{\circ}, 6^{\circ}$ e $8^{\underline{o}}$ dias de aferição, quando comparados ao grupo controle. Quando se dobrou a área da ferida, novamente se observou que ambos os grupos-teste produziram redução estatisticamente significativa da área a partir do $6^{0}$ dia de determinação até o processo final de cicatrização. Os resultados comprovam que o Sanativo ${ }^{\circledR}$ possui propriedade cicatrizante. Os autores atribuíram tais efeitos à presença de altos teores de tanino do angico e aroeira.

Recentemente, outro estudo ${ }^{(2)}$ foi realizado com o objetivo de avaliar o aspecto histológico dos alvéolos dentários de incisivos superiores de ratos portadores de alveolite após uma extração dental e tratados ou não com Sanativo ${ }^{\circledR}$. Foram utilizados 36 ratos Wistar machos com idade entre 70 e 90 dias e peso entre 280 e 330 gramas. Estes animais foram divididos em 02 grupos de 18 animais, sendo que no primeiro os animais foram submetidos à alveolite dental experimental e fizeram a ingestão de água (não-tratados), e no segundo, os animais foram submetidos à alveolite dental experimental e fizeram a ingestão do Elixir Sanativo $^{\circledR}$. Em seguida, cada um desses grupos foi subdividido em 3 subgrupos de 6 animais de acordo com o tempo de sacrifício dos mesmos, sendo grupo A (ratos sacrificados no $6^{\underline{0}}$ dia da comprovação da alveolite dental), B (ratos sacrificados no $15^{\circ}$ dia da comprovação da 
alveolite dental) e grupo $\mathrm{C}$ (ratos sacrificados no $21^{\circ}$ dia da comprovação da alveolite dental). Os pesquisadores concluíram que o Elixir Sanativo ${ }^{\circledR}$ contribuiu para que o processo de cicatrização fosse o mais próximo possível dos padrões de normalidade, ou seja, mais semelhante ao processo de cicatrização do alvéolo (sem infecção), sendo que os melhores resultados foram evidenciados nas amostras de 21 dias.

Com o propósito de realizar uma análise comparativa da eficácia clínica antiinflamatória do Sanativo ${ }^{\circledR}$ e da clorexidina após exodontia de molares inferiores, Azoubel et al. ${ }^{(15)}$ realizaram um estudo com 60 voluntários sistemicamente saudáveis com indicação de exodontia de um molar inferior, e que não tivessem realizado qualquer terapia farmacológica nos últimos 7 dias antes da cirúrgia. Os voluntários receberam frascos com antissépticos Sanativo $^{\circledR}$ ou Periogard ${ }^{\circledR}$ de forma aleatória para uso no pós-operatório a partir de 24 horas do término da cirurgia e fizeram uso dos mesmos (Sanativo ${ }^{\circledR}$ ou Periogard ${ }^{\circledR}$ ) por 07 dias. Subseqüentemente, os pacientes foram avaliados em três momentos: previamente a cirurgia; 48 horas após a cirurgia e 07 dias após a cirurgia. Os autores concluíram que o Sanativo ${ }^{\circledR}$ apresentou ação analgésica e antiinflamatória no pós-operatório de cirurgias de molares inferiores, sendo superior a clorexidina em relação a eficácia terapêutica nesses aspectos.

$\mathrm{O}$ objetivo do presente estudo foi avaliar clinicamente o efeito tópico do fármaco Sanativo ${ }^{\circledR}$ nos alvéolos de molares inferiores no período pós-operatório.

\section{ESTUDO EXPERIMENTAL}

Este estudo se propôs a avaliar clinicamente o uso do Sanativo ${ }^{\circledR}$ nos alvéolos de molares inferiores de pacientes do ambulatório da Disciplina de Cirurgia Bucomaxilofacial (CBMF) do curso de Odontologia da Escola Bahiana de Medicina e Saúde Pública (EBMSP) como solução tópica utilizada no período pós-operatório. Este estudo foi submetido ao Comitê de Ética em Pesquisa da EBMSP e aprovado para execução pelo parecer 140/2008.

\subsection{Materiais e Métodos}

2.1.1 Desenho do estudo - Este foi um estudo prospectivo, randomizado, duplo cego e placebo-controlado. Um residente em CBMF ficou responsável pela seleção de pacientes, execução dos procedimentos clínicos e avaliações dos dados e um acadêmico de Odontologia 
Azoubel, Ribeiro. Efeito local do uso do schinus terebinhthifolius e associações (Sanativo®) no pós-operatório de exodontias de molares inferiores

responsável pelo registro e controle dos pacientes, randomização e dispensação dos medicamentos.

2.1.2 Critérios de inclusão - foram selecionados, por demanda espontânea, 60 pacientes de ambos os sexos, com idades entre 18 e 60 anos, sistemicamente saudáveis, que apresentaram necessidade de exodontia de um molar inferior. Terceiros molares necessitavam estar erupcionados.

2.1.3 Critérios de exclusão - foram excluídos da pesquisa, pacientes alérgicos a um ou mais fármacos empregados no estudo; nutrizes/gestantes; pacientes portadores de patologia sistêmica sem controle; pacientes que faltaram à consulta de revisão; não concordância com o Termo de Consentimento Livre e Esclarecido; uso de anti-inflamatórios ou antibióticos nos últimos 07 dias; tabagistas; Terceiros molares com necessidade de uso de técnica $3^{\mathrm{a}}$; Unidades com pericoronarite.

2.1.4 Estabelecimento dos grupos experimentais - Os 60 pacientes que preencheram os critérios de inclusão/exclusão e que formaram a amostra final foram aleatoriamente (por sorteio) alocados para um dos quatro grupos experimentais. Todos os pacientes de cada grupo fizeram uso de $15 \mathrm{~mL}$ da determinada solução durante 01 minuto, três vezes ao dia por sete dias, 30 minutos após a escovação. Os voluntários do Grupo teste (T) fizeram uso do Sanativo $^{\circledR}$, no Grupo controle positivo A (CPA) fizeram uso do Malvatricin ${ }^{\circledR}$ (Laboratório Daudt Oliveira Ltda., Rio de Janeiro, Rio de Janeiro, Brasil). Já aqueles do grupo controle positivo $\mathrm{B}(\mathrm{CPB})$ bochecharam Clorexidina a $0,12 \%$ (03 vezes ao dia para padronização, já que a posologia é 02 vezes ao dia). Finalmente o Grupo controle (C), foi instruído a fazer uso de solução fisiológica $(\mathrm{NaCl})$. Todos os pacientes foram orientados sobre a forma de uso do medicamento e a não bochecharem nas primeiras 48 horas após a intervenção cirúrgica, e sim, apenas manter o colutório na cavidade oral pelo tempo determinado (Figura 1). 


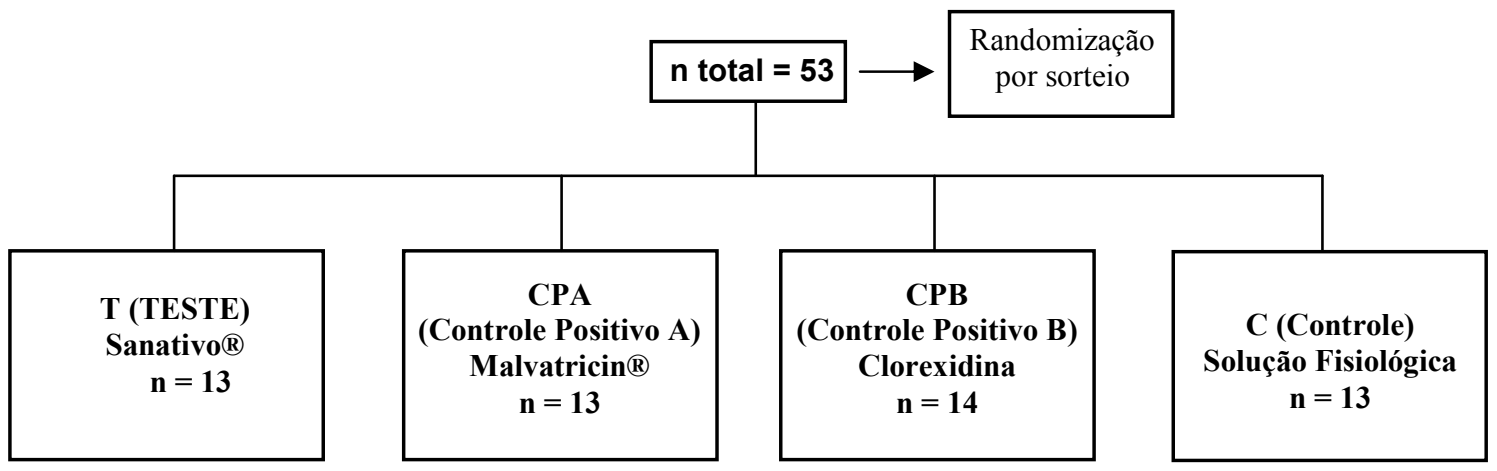

\subsubsection{Fiscalização da adesão ao tratamento farmacológico / Controle de eventos adversos}

- A dispensação dos medicamentos foi feita por um profissional não envolvido diretamente com o estudo, o qual também executou a randomização. Desta forma, o examinador foi cego em relação ao estudo. Os pacientes também não souberam a que grupo experimental pertencia, já que os fármacos foram acondicionados em frascos graduados de cor âmbar e que não continham a informação sobre o medicamento.

O controle da adesão ao tratamento farmacológico foi feito pelo controle volumétrico do conteúdo dos frascos e, além disso, um aluno do curso de Odontologia foi encarregado de telefonar diariamente para os pacientes a fim de lembrar-lhes sobre o uso e registrar possíveis eventos adversos (Anexo 4).

2.1.6 Procedimento cirúrgico (exodontia) - $O$ ato cirúrgico foi realizado pelo mesmo operador, residente em $\mathrm{CBMF}$, calibrado e experiente e que não sabia a que grupo cada voluntário pertencia. Após anestesia por bloqueio regional dos nervos alveolar inferior e bucal além de infiltrativa local na gengiva da região a ser operada, uma incisão intrasulcular foi realizada ao redor da unidade dentária seguida de descolamento mucoperiosteal. A exodontia ocorreu por meio de técnicas com alavancas ou fórceps sem a realização de odontossecção. A ferida cirúrgica não foi suturada. Aqueles que necessitaram da técnica terceira foram excluídos da pesquisa.

2.1.7 Tempos experimentais $-\mathrm{T}_{0}$ : imediatamente após o procedimento cirúrgico; $\mathrm{T}_{1}: 48$ horas após a intervenção cirúrgica; $T_{2}$ : 07 dias após a intervenção cirúrgica. 
2.1.8 Parâmetros avaliados - tamanho da ferida (através um Compasso Castroviejo - marca Golgran ${ }^{\circledR}$ com precisão decimal) e aspecto inflamatório visual. O parâmetro foi avaliado sempre pelo mesmo examinador, o qual foi previamente calibrado por um profissional experiente.

2.1.9 Orientação de Higiene Oral - Todos os pacientes foram orientados antes da cirurgia quanto aos cuidados da higiene oral e foram apresentados os métodos disponíveis e indicados para esse fim. Foram fornecidos escovas e fio dental.

2.1.10 Análise estatística / Descritiva - Inicialmente foi realizada a análise exploratória dos dados para verificar a homogeneidade das variâncias e para determinar se os erros experimentais apresentavam distribuição normal (parâmetros da Análise de Variância). A análise estatística inferencial foi feita por meio da Análise de Variância em esquema de Parcela subdividida no tempo. Esta análise foi feita no programa estatístico SAS, versão 9.1, com nível de significância de 5\%. A avaliação da ferida também foi feita igualmente e relatada de forma descritiva.

\section{RESULTADOS / DISCUSSÃO}

Foram triados inicialmente um total de 72 pacientes. Destes, 12 não preenchiam os critérios de inclusão ou possuíam algum critério de exclusão, constituindo um grupo inicial de 60 pacientes. Do último grupo citado, 7 voluntários não retornaram para a reavaliação. Dessa forma, a amostra final foi constituída de 53 participantes e todos foram incluídos na análise.

\subsection{Análise do tamanho da ferida / Aspecto inflamatório visual}

A tabela 1 apresenta a média e desvio-padrão obtidos nos grupos experimentais. 
Azoubel, Ribeiro. Efeito local do uso do schinus terebinhthifolius e associações (Sanativo®) no pós-operatório de exodontias de molares inferiores

Tabela 1 - Média (desvio-padrão) da redução do tamanho do alvéolo em mm apresentada pelos grupos experimentais.

T1 (2 dias após

cirurgia)

Clorexidina

Malvatricin

Soro fisiológico

Sanativo

4.03 (1.44) Aa

$3.22(0.82) \mathrm{Ba}$

3.33 (1.24) Ba

$3.43(1.05) \mathrm{Ba}$
T2 (7 dias após cirurgia)

Medianas seguidas de letras distintas representam significância estatística (Anova em esquema de parcela subdividida/Tukey, alfa $=5 \%)$. Maiúsculas comparam tratamentos e minúsculas comparam tempos.

A interação estatística entre os fatores tratamento e tempo foi estatisticamente significativa $(\mathrm{p}<0.0001)$, indicando dependência entre os efeitos de um fator sobre os níveis do outro. Esta interação foi desdobrada pelo teste de Tukey.

De acordo com a análise estatística, foram observadas diferenças entre os tempos nos quatro tipos de tratamento. Portanto, em todos os tratamentos, houve redução do tamanho da ferida.

Esses dados já eram previstos, uma vez que de fato é esperada uma redução do tamanho global do alvéolo após procedimentos de exodontia devido ao processo de reparação tecidual por $2^{\mathrm{a}}$ intenção. Afirma-se que, fisiologicamente, o alvéolo sofre o fenômeno de contração que, por si só, reduz o tamanho da ferida em 5-10\% em 6 semanas. Este processo inicia-se pela formação de uma rede de fibroblastos contendo actina na margem da ferida, que se diferenciam em miofibroblastos com características de células musculares lisas onde sua contração diminui os espaços entres as margens dérmicas da ferida. Este fenômeno de resposta cicatricial se deve à ação do sistema imunológico e das células de defesa, com participação de mediadores químicos. Portanto, essa resposta "espontânea" ocorreu em todos os pacientes dos grupos, uma vez que os incluídos no estudo eram imunocompetentes. ${ }^{(16)}$

Dentro deste contexto, a literatura é unânime em afirmar que a cicatrização da ferida cirúrgica após exodontia ocorre em média de 4-6 meses uma vez que a remodelação óssea ocorre. Porém, logo após a exodontia, em algumas horas, o coágulo sanguíneo preenche o alvéolo, tendo importância biológica no processo de cicatrização da ferida uma vez que se dá 
início ao desenvolvimento de tecido conjuntivo no local. O tecido de granulação é formado e, mais adiante, é substituído por tecido ósseo. ${ }^{(17,18)}$

Ainda em relação ao parâmetro clínico tamanho da ferida, mas direcionando a interpretação dos dados para os medicamentos empregados 2 dias após a cirurgia (T1), o grupo (CPB) apresentou valor de redução global do alvéolo estatisticamente superior ao dos demais grupos que, por sua vez, foram semelhantes entre si. Esses dados confirmam a ação terapêutica da clorexidina, que é considerada como padrão-ouro do controle químico supragengival devido às suas propriedades antibacterianas. Usada em procedimentos de exodontias nos períodos pré, trans e pós-operatório para reduzir a incidência de alveolites e infecções, ${ }^{(19)}$ ela é ativa contra bactérias gram positivas/negativas, aeróbios e anaeróbios facultativos, fungos, leveduras e vírus lipofílicos. Esta substância exibe efeito bactericida imediato, e possui excelente substantividade. Seu efeito antimicrobiano é dado através de cargas positivas no $\mathrm{pH}$ fisiológico, o que desestabiliza a parede celular das bactérias e altera o equilíbrio osmótico das mesmas resultando em precipitação citoplasmática e morte celular das bactérias. ${ }^{20,21)}$

De fato, recente revisão reiterou que o uso do bochecho de clorexidina reduz significativamente o risco de bacteremia pós-exodontia. ${ }^{(21)}$ A partir do conhecimento sobre o mecanismo de ação bactericida do referido agente, é plausível sugerir que seu potente efeito antimicrobiano gera conseqüente efeito anti-inflamatório, uma vez que a eliminação de patógenos na área da ferida cirúrgica reduz a agressão local (efeitos diretos e indiretos) sobre os tecidos manipulados, o que possivelmente virá a favorecer o processo de reparação.

Em relação à eficácia terapêutica do medicamento-teste $\left(\right.$ Sanativo $\left.^{\circledR}\right)$, não foi observado efeito comparável à clorexidina sobre o parâmetro avaliado (redução do tamanho da ferida). Esse dado, de certa forma, se contrapõe aos resultados encontrados em estudo prévio realizado, onde foi observado efeito anti-inflamatório e analgésico do Sanativo 48 horas após a cirurgia, tendo sido comparável ao efeito promovido pela clorexidina. ${ }^{(15)}$ No entanto, é cabível pontuar que, neste estudo, o tamanho de ferida não foi objeto de estudo e sim a avaliação dos sinais e sintomas sistêmicos relacionados ao processo inflamatório. Dessa forma, uma comparação fidedigna dos resultados é impossibilitada.

Ainda em relação aos resultados apresentados pelo grupo teste no que se refere ao tamanho da ferida, não foi possível confirmar o potencial efeito local do Sanativo como observado em estudo realizado por Coutinho et al. ${ }^{(22)}$, quando se avaliou o efeito do extrato hidroalcoólico da aroeira no processo de cicatrização de anastomoses colônicas em ratos e 
também se contradizem a outros trabalhos desenvolvidos na área da Medicina que demonstraram que a maior redução do alvéolo pós-cirúrgico se deve às propriedades antiinflamatórias do Sanativo ${ }^{\circledR}$. 23$)$

Uma hipótese plausível que pode justificar a diferença encontrada neste estudo no âmbito da Medicina é a localização da ferida. No presente estudo a ferida estava situada em uma superfície mucosa e em um ambiente por onde permeia a saliva e outras substâncias, que hipoteticamente podem afetar o princípio ativo, no sentido de neutralizar, antagonizar ou reduzir o efeito terapêutico do medicamento-teste (Sanativo). Este é um aspecto diferencial em relação à clorexidina, a qual já foi exaustivamente estudada no ambiente bucal e que demonstra ampla eficácia e estabilidade neste meio. Dificulta também a análise e possíveis inferências, o fato dos dados apresentados serem inéditos, ou seja, nenhum outro trabalho avaliou este medicamento intraoralmente quanto ao seu efeito local sobre feridas cirúrgicas. Soma-se a isso a constatação, a partir dos resultados de T1 (2 dias após o procedimento cirúrgico), quanto à necessidade de uso de um agente químico que favoreça o processo cicatricial e minimize a possibilidade de infecção pós-operatória. Em outras palavras, embora o medicamento-teste (Sanativo) não tenha promovido um incremento na redução do tamanho global do alvéolo, a clorexidina confirmou-se eficaz neste propósito, o que reitera e torna plausível a sua racional indicação clínica, sobretudo em um período onde é evidente a dificuldade e receio por parte do paciente em realizar uma higienização adequada como afirma López-Jornet et al. ${ }^{(24)}$ Ainda importa o fato de que é possível esperar menos desconforto e menor incidência de infecção pós-operatória quando há fechamento precoce da cavidade. $^{(19)}$

Os resultados da redução do tamanho da ferida, 7 dias após a cirurgia, evidenciaram que os grupos que usaram clorexidina (CPB) e soro fisiológico (C) apresentaram os maiores valores de redução. A interpretação de tais resultados conduz para o entendimento que neste tempo experimental, o uso de agentes para controle químico não apresentou efeito diferencial, uma vez que o soro fisiológico, usado como controle neste estudo, sabidamente não tem princípio ativo ou terapêutico. Portanto, é possível sugerir que nessa fase pós-cirúrgica, em que o paciente consegue ter mais acesso e menos receio na higienização, não seja realmente essencial o uso de um medicamento com atividade bactericida ou anti-inflamatória. Neste contexto, renomados autores colocam que é imperativa a criteriosa avaliação da razão riscobenefício bem como da razão custo-benefício quanto ao uso de fármacos por tempo prolongado para este fim. ${ }^{(21)}$ Ainda sobre este tempo de uso, é cabível a crítica de que a 
normatização de tais condutas deve ser pautada na prévia comprovação da sua plausibilidade biológica, que até o momento carece de evidências mais consistentes. Em suma, é imperativa a realização de estudos que comprovem, através de exames microbiológicos e de padrões inflamatórios, a necessidade de uso de colutórios por 07 dias após a cirurgia, já que a determinação atual do tempo de uso é ditada apenas pela "tradição de indicação".

Quanto ao parâmetro aspecto inflamatório visual, foi possível observar, em indivíduos pertencentes ao grupo teste, a formação de uma "membrana esbranquiçada" que cobria praticamente todo o alvéolo cirúrgico desde o $2^{\circ}$ dia (T1) e que se manteve até 7 dias após a cirurgia (T2) (Figura 2), aspecto este não evidenciado nos alvéolos dos pacientes dos demais grupos experimentais. Este achado está em consonância com a literatura correlata, que suporta que essa membrana é formada a partir de taninos presentes no Sanativo ${ }^{\circledR}$. Estudos ${ }^{(23)}$ sustentam o seu poder antisséptico pode ser explicado por sua capacidade de precipitar as proteínas das células superficiais das mucosas dos tecidos, formando uma camada protetora (complexo tanino-proteína e/ou polissacarídeo) sobre a pele ou mucosa danificada, impedindo assim o desenvolvimento de microorganismos. Haslam ${ }^{(25)}$ corrobora essa premissa ao afirmar que o uso de Sanativo ${ }^{\circledR}$ gera a formação de um "tampão" auxiliado pela formação do coágulo, onde, por impedimento da ação de fatores extrínsecos, há um favorecimento à mais rápida e saudável cicatrização proporcionando ao paciente um pós-operatório mais confortável.

Figura 2 - Paciente do Grupo Teste 48 hs (T1) após a cirurgia. Alvéolo pós-cirúrgico com presença de "tampão".

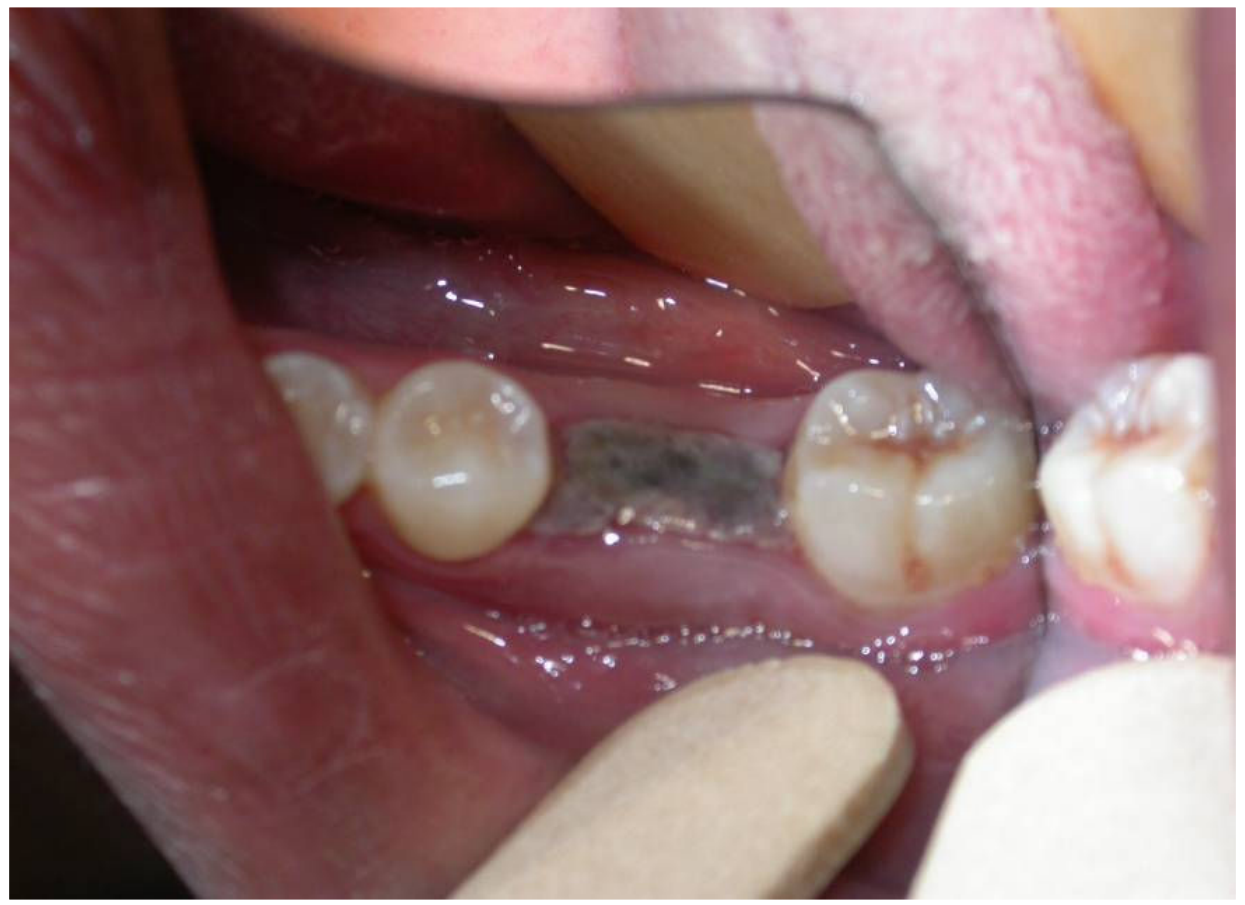


A despeito da presença da membrana, a hipótese de efeito anti-inflamatório incremental local esperado no grupo teste (Sanativo) não foi confirmada. A tradução clínica deste resultado foi o fato de que supuração local não foi vista clinicamente em qualquer dos pacientes independente do grupo experimental, ou seja, todos os grupos foram semelhantes entre si.

Diante da escassez de trabalhos que envolvem o uso do Sanativo ${ }^{\circledR}$ na mucosa oral é possível constatar a necessidade da realização de outros trabalhos com o medicamento Sanativo ${ }^{\circledR}$ em procedimentos odontológicos a fim de esclarecer sobre o seu potencial efeito anti-inflamatório em feridas cirúrgicas.

\section{CONCLUSÃO}

O uso do Sanativo ${ }^{\circledR}$ não apresentou benefício adicional na redução do tamanho da ferida. Embora macroscopicamente tenha havido a formação de uma "membrana" sobre a ferida cirúrgica, isto não se traduziu em diferença no aspecto inflamatório visual.

\section{REFERÊNCIAS}

1 David JPL, Nascimento JAP, David JM. Produtos Fitoterápicos: uma perspectiva de negócio para a indústria, um campo pouco explorado pelos farmacêuticos. Infarma 2004; 16(9-10): 71-6.

2 Pessoa VS. Avaliação do elixir Sanativo ${ }^{\circledR}$ sobre o processo de alveolite dental induzida em ratos (Rattus norvegicus albinus) [Monografia]. Recife (PE): Centro de Ciências da Saúde da Universidade Federal de Pernambuco; 2008.

3 Matos FJA. O formulário fitoterápico do Professor Dias da Rocha. 2 ed. Fortaleza: UFC edições; 1997.

4 Santos SC, Mello JCP. Taninos. IN: SIMÕES, C.M.O. et al. Farmacognosia: da planta ao medicamento. 2 ed. Porto Alegre: UFRGS; 2000.

5 Chung KT, Wong TY, Wey CI, Huang YW, Lin Y. Tannis and human health: A review. Food Science and Nutrition 1998; 38: 421-64.

6 Rodrigues RF, et al. Estudo comparativo dos frutos de "Pink pepper" (Schinnus terebinthifolius Raddi) and Black Pepper(Pepper nigrum L.). Lecta-USF 1998; 16(2): 9-30.

7 Desmarchelier C, Romão RL, Coussio J, Ciccia G. Antioxidant and free radical scavenging activities in extracts from medicinal trees used in the "Caatinga" region in northeastern Brazil. J. Ethnopharmacol 1999; 67: 69-77. 
Azoubel, Ribeiro. Efeito local do uso do schinus terebinhthifolius e associações (Sanativo®) no pós-operatório de exodontias de molares inferiores

8 Soleas GF, Grass L, Josephy PD, Goldberg DM, Diamandis EP. A comparison of the anticarcinogenics properties of four red wine polyphenois. Clinical Biochemistry 2002; 35: 119-24.

9 Yen G, Duh P, Tsai H. Antioxidant and pro-oxidant properties of ascorbic acid and gallic acid. Food Chemistry 2002; 1: 1-6.

10 Lorenzi H. Árvores brasileiras: manual de identificação e cultivo de plantas arbóreas nativas do Brasil. 2 ed. São Paulo: Plantarum; 1998.

11 Choi EM, Hwang J.K. Investigations of anti-inflammatory and anticonceptive activities of Piper cubeba, Physalis angulata and Rosa hybrida. J Ethnopharmacol 2003; 89: 171-5.

12 Pio Corrêa M. Dicionário das plantas úteis do Brasil e das exóticas cultivadas. Imprensa Nacional. Instituto Brasileiro de Desenvolvimento Florestal, 1978a; 1: 408-9.

13 Pio Corrêa M. Dicionário das plantas úteis do Brasil e das exóticas cultivadas. Imprensa Nacional. Instituto Brasileiro de Desenvolvimento Florestal, 1978b; 1: 70-1.

14 Wanderley AG, et al. Avaliação farmacológica e toxicológica pré-clínica do fitoterápico Sanativo ${ }^{\circledR}$ [Monografia]. Recife(PE): Universidade Federal de Pernambuco; 2005.

15 Azoubel E, Ribeiro CO, Filho LATV, Azoubel MCF, Sardinha SC. Avaliação clínica do potencial antiinflamatório da aroeira (Schinnus terebentifolius) e da clorexidina em exodontias de molares inferiores. Rev Bras Cir Traumatol Buco-Maxilo-Fac 2006; 3(3): 85-9.

16 Robins SL, Cotran RS. Bases Patológicas das Doenças. Rio de Janeiro: Elsevier; 2005. P.116-9.

17 Del Fabbro M, Bortolin M, Taschieri S. Is autologous platelet concentrate beneficial for post-extraction socket healing? A systematic review. Int J Oral Maxillofac Surg 2011; 40: 891-900.

18 Li YQ, Shan ZC. Initial Study on Facilitating Wound Healing After Tooth Extraction by Using Microbial Fiber Membrane-Flagyl. J Oral Maxillofac Surg 2011; 69: 994-1002.

19 Yengopal V, Mickenautsch S. Chlorhexidine for the prevention of alveolar osteitis. Int $\mathbf{J}$ Oral Maxillofac Surg 2012; 41: 1253-1264.

20 Agarwal A, Nelson TB, Kierski PR, Schurr MJ, Murphy CJ, Czuprynski CJ, et al. Polymeric multilayers that localize the release of chlorhexidine from biologic wound dressings. Biomaterials 2012; 33: 6783-6792.

21 Campos MLG, Corrêa MG, Ruiz KGS, Sallum EA, Sallum AW. Estado atual da clorexidina na terapia periodontal. Perionews 2012; 6(3): 279-84. 
Azoubel, Ribeiro. Efeito local do uso do schinus terebinhthifolius e associações (Sanativo®) no pós-operatório de exodontias de molares inferiores

22 Coutinho IHILS, Torres OJM, Matias JEF, Coelho JCU, Júnior HJS, Agulham MA, et al. Efeito do extrato hidroalcoólico de aroeira (schinus terebinthifolius raddi) na cicatrização de anastomoses colônicas: estudo experimental em ratos. Acta Cir Bras 2006; 21: 4-9.

23 Lima CR, Costa-Silva JH, Lyra MMA, Araújo AV, Arruda VM, Dimech GS, et al. Atividade Cicatrizante e Estudo Toxicológico Pré-Clínico do Fitoterápico Sanativo ${ }^{\circledR}$. Acta Farm Bonaerense 2006; 25(4): 544-9.

24 López-Jornet P, Camacho-Alonso F. Martinez-Canovas A: Clinical Evaluation of Polyvinylpyrrolidone Sodium Hyalonurate Gel and $0.2 \%$ Chlorhexidine Gel for Pain After Oral Mucosa Biopsy: A Preliminary Study. J Oral Maxillofac Surg 2010; 68: 2159-2163.

25 Haslam E. Natural poplyphenois (vegetable tannins) as drugs and medicines: possible modes of action. Journal of Natural Products 1996;59:205-15. 


\section{PARECER DO COMITÊ DE ÉTICA EM PESQUISA}
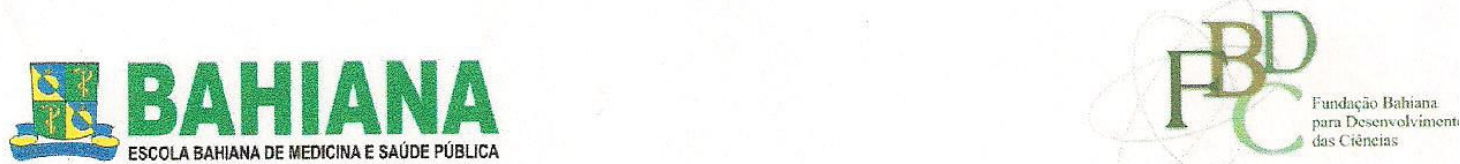

\section{COMITÊ DEÉTICA EM PESQUISA}

Ofício n 012/2009

Salvador, 12 de fev ereiro de 2009.

\section{REFERENTE AO PROT. DE PESQUISA No 140/2008}

\section{"Efeito do uso do Sanativo (B no pós operatório de exodontias de molarfes inferiores"}

"Senhor Pesquisador,

O CEP-Comitê de Ética em Pesquisa da Fundação Bahiana para desenvolvimento das Ciências, após análise do ponto de vista bioético do Protocolo acima citado, segundo a Resolução 196/96 do Conselho Nacional de Ética em Pesquisa (CONEP-CNS-MS), considera o referido Protocolo com PENDÊNCIAS, abaixo citadas, que deverão ser sanadas num prazo máximo de 60 (sessenta) dias:

01.Corrigir o TCLE acrescentando: nome, endereço e local para assinatura do pesquisador responsável (orientador), local para impressão digital e endereço correto do CEP-EBMSP (Avenida D. João VI, 274-Brotas);

02..Enviar carta de solicitação de apreciação de protocolo de pesquisa a este CEP, com título da pesquisa correto e assinatura do pesquisador responsável;

03. Nome e assinatura no formulário resumo pelo pesquisador responsável (orientador).

Profa. Dra. Lueíra Maratopes Crisóstomo

Coordenadora do CEP/FBDC.

Ilmo. Sr.

PROF. EDUARDO AZOUBEL

Rua dos Prazeres, 238 - Caji

CEP.42.700-000 - Salvador-Bahia.. 